\title{
PLURALISMO JURÍDICO E CONTRA-HEGEMONIA DOS POVOS REMANESCENTES DE QUILOMBOS*
}

\author{
LEGAL PLURALISM AND COUNTER-HEGEMONY OF THE REMAINING QUILOMBOS
}

\author{
Júlio César Lopes ${ }^{1}$ \\ Antonio Carlos Wolkmer ${ }^{2}$
}

\begin{abstract}
Resumo: O presente texto tem como objeto a discussão sobre aspectos do Pluralismo Jurídico e a contra-hegemonia dos povos remanescentes de quilombos. Busca (a) analisar como se estabelece a normatividade insurgente, suas vertentes e caminhos; (b) demonstrar que desde a África até a atualidade o povo negro permanece na luta contra a exploração. Quanto à metodologia, utilizou-se o método dedutivo de abordagem e o de procedimento, o monográfico, com a técnica de pesquisa bibliográfica em obras nacionais e estrangeiras. A discussão e a sua problematização compreende: primeiramente, a questão da natureza do pluralismo jurídico; na sequência, a diáspora do povo negro, e, por último, as causas e os processos de insurgência que engendram novas normatividades. A visão europeia que parte da perspectiva de sua história e cultura irradiou ao mundo uma inferiorização, cabendo povo negro, desde a África até o presente, resistir para manter sua identidade e proteger suas comunidades.
\end{abstract}

Palavra-chave: Pluralismo jurídico; Direito insurgente; Contra-hegemonia; Emancipação; Remanescentes de Quilombos.

\begin{abstract}
This text aims to discuss aspects of Legal Pluralism and the counter-hegemony of the remaining quilombos. It seeks (a) to analyze how insurgent normativity is established, its aspects and paths; (b) demonstrate that from Africa to the present day the black people remain in the fight against exploitation. As for the methodology, the deductive approach method and the procedure method, the monographic one, were used, with the technique of bibliographic research in national and foreign works. The discussion and its problematization
\end{abstract}

\footnotetext{
* Artigo submetido em 24/11/2019 e aprovado para publicação em 20/07/2020.

${ }^{1}$ _Professor do Curso de Direito da UNESC - Universidade do Extremo Sul Catarinense. Mestre em Direitos Humanos e Sociedade, integrante do Grupo de Pesquisa NUPEC da UNESC-SC. Advogado. E-mail: jclopes@unesc.net. ORCID: https://orcid.org/0000-0002-3253-0167.

${ }^{2}$ Professor dos Programas de Pós-Graduação em Direito da UNILASALE-RS (Mestrado e Doutorado em Direito), da UNESC-SC, onde coordena seu Mestrado em Direitos Humanos e o Grupo de Estudos NUPEC, e da UFSC (colaborador titular aposentado). Doutor em Direito. Membro do Instituto dos Advogados Brasileiros (RJ). É pesquisador nível 1-A do CNPq, e consultor ad hoc da CAPES. Membro da Sociedad Argentina de Sociologia Jurídica. Igualmente integrante de GT - "Crítica Jurídica y Conflictos Sociopolíticos", do Conselho Latino-americano de Ciências Sociais (CLACSO, Buenos Aires/México). Membro da International Political Science Association (IPSA, Canada), and of the Research Committee on Sociology of Law (RCSL). Professor visitante de Cursos de Pós-graduação em várias universidades do Brasil e do exterior (Argentina, Peru, Colômbia, Chile, Equador, Venezuela, Costa Rica, México, Espanha e Itália). Autor de diversos livros, entre os quais: Constitucionalismo Latino-americano: tendências contemporâneas. (Co-organizador). Curitiba: Juruá, 2013; História do Direito: tradição no ocidente e no Brasil. 11. ed. Rio de Janeiro: Forense, 2019; Introdução ao Pensamento Jurídico Crítico. 9. ed. São Paulo: Saraiva, 2015; Pluralismo Jurídico: - fundamentos de uma nova cultura no Direito. 4. ed. São Paulo: Saraiva, 2015. E-mail: acwolkmer@gmail.com. ORCID: http://orcid.org/0000-0003-1861-5305.
} 
comprises: first, the question of the nature of legal pluralism; then, the diaspora of the black people, and, finally, the causes and processes of the insurgency that engender new norms. The European vision that starts from the perspective of its history and culture radiated an inferiority to the world, leaving black people, from Africa to the present, to resist to maintain their identity and protect their communities.

Key-word: Legal pluralism; Insurgent law; Counter-hegemony; Emancipation; Quilombos remnants.

\section{Introdução}

É incompreensível entender uma coletividade quando quem pretende alcançar essa compreensão fica ou se comporta de forma longínqua, não considera a multiplicidade e a biografia do grupo social. Entre o século XVII e XVIII originou-se uma manifestação de ruptura cuja centralidade reside na primazia da construção de uma sociedade burguesa, “[...] modo de produção capitalista, da ideologia liberal-individualista e da centralização política, através da figura de um Estado Nacional Soberano" (WOLKMER, 2015, p. 24).

Nesse sentido, considerando que o direito é a manifestação do modo de solucionar conflitos inerentes a qualquer sociedade, é necessário que seja levado em consideração que nos mais diversos momentos e fases da história da humanidade, especialmente no mundo ocidental fundamentado sob sólida influência e colonização europeia, a normatividade foi coordenada de maneira que não foram considerados outros povos, os quais, ficaram à margem ou fora do amparo e interesses do direito reconhecido e hegemônico (WOLKMER, 2015, p. 13-14, 24).

No início da última metade do século XX, o monismo jurídico - após quase três séculos - começa apresentar insuficiências de eficácia e de respostas às demandas sociais, diante da complexidade das formas de vida e dos novos paradigmas de conhecimento, passando por instabilidades globais e rupturas estruturais. Esse desgaste da centralidade do formalismo legal ou crise de hegemonia é que faz reascender e destacar o pluralismo jurídico como instrumental de normativa alternativa para além do Estado, concebidas pelas necessidades das coletividades em um viés democrático, flexível e descolonial. Surge um pluralismo que privilegia a atuação comunitária e vislumbra o direito como manifestação de valores que reflete emancipação e participação de múltiplos sujeitos coletivos na criação e aplicação normativa (WOLKMER, 2015, p. 60-61, 80-82).

De forma mais detalhada sobre o panorama do pluralismo em geral é necessário ponderar que a pluralidade ou pluralismo está relacionada à insurgência e variedade de 
experiências geradas por necessidades e lutas sociais. A diversidade de visões que se visualiza causa desconfiança, o que em certas situações pode levar a insegurança da sociedade; mas, como argumenta Sartori (2009, p. 63), os desacordos e distinções de ideias são impulsionadores e trazem desenvolvimento à sociedade. De forma inversa, a invariabilidade e a uniformidade não produz avanços.

Diante desses aspectos, o objeto delimitado do presente texto buscará introduzir um olhar inicial sobre o pluralismo de tipo insurgente e a contra-hegemonia dos povos remanescentes de quilombos desde a África até o Brasil contemporâneo.

Assim, procurou-se destacar nos objetivos como se estabelece o pluralismo normativo insurgente, suas fontes e seus percursos. Posteriormente, demonstra-se que desde o período na África até a atualidade o povo negro passa por constantes lutas contra um sistema de dominação e segregação racial.

Com essas assertivas, chega-se ao principal problema da pesquisa: se é possível compreender o pluralismo legal insurgente como a práxis constante e contra-hegemônica de cinco séculos dos povos negros.

O direito insurgente é sustentado originariamente nas teorias críticas do direito, sobretudo, no viés latino-americano com vinculação à descolonialidade (PAZELLO, 2018, p. $155)$.

Partindo da correlação das circunstâncias expostas, um panorama do que seja um direito insurgente não deve considerar tão somente a concretude normativa, no aspecto técnico-formal, mas é necessário um direito mais substancial, que seja proveniente da insurgência ou rejeição sobre o que está posto -o que está corrente é o direito a serviço de um agir e de uma visão dominante - que não considera o trabalhador da fábrica, o campesino ou outros grupos omitidos ou setores populares (PRESSBURGER, 1990, p. 61).

A partir dos anos 80, com a redemocratização do país, a discussão em torno dos remanescentes dos quilombos ganhou superfície com a insistência e provocação de movimentos negros, apoiados por intelectuais e ativistas. Em uma recontextualização do Brasil, a visão do negro enquanto estigmatizado, passa por uma nova perspectiva e os remanescentes de quilombos são a expressão viva de que a sociedade deve compreender que, desde a formação dos primeiros quilombos, ajuntamentos ou mocambos, no início da colonização europeia, o que se quer é a libertação, que passa pela emancipação e cidadania desses coletivos, que ao longo de séculos vêm sendo constituídas pela luta, resistência e solidariedade (LEITE, 1999, p. 133). 
Em face dessas considerações, importa considerar três momentos a serem tratados: (1) A questão de um pluralismo normativo como possibilidade insurgente; (2) Diáspora do povo negro: da África ao brasil; e (3) Cinco séculos de insurgência contra-hegemônica.

O marco teórico desse artigo é a teoria do Pluralismo Jurídico. O método de abordagem empregado é o raciocínio indutivo-dedutivo, sendo que o estudo optou por procedimento metodológico bibliográfico-investigativo, fundamentado em uma análise da realidade concreta. $\mathrm{O}$ perfil exploratório está presente nas técnicas de pesquisa das obras de referência, assumindo um perfil interdisciplinar que articula Direito, sociologia e política.

\section{A questão do pluralismo normativo como possibilidade de insurgência}

É inverossímil pensar uma nação que não tenha suas bases apoiadas no pluralismo, que é a possibilidade da diversidade, do respeito à diferença e a da democracia pautada na inclusão (SIMÓN, 2018, p. 2, 26-27, 38). O pluralismo é uma direção que salvaguarda a independência de compreender o mundo, portanto, desafia as pessoas e instituições a vislumbrarem outras possibilidades (SARTORI, 2009, p. 62).

Convém registrar que embora haja um significativo número de concepções sobre o pluralismo jurídico, sendo de algum modo considerado um termo polissêmico, ante sua amplitude no tempo e na origem, que pode ser utilizado tanto dentro de uma formulação política quanto jurídica, ele constitui uma abertura de formulação que corresponde e é condizente com a recusa de um Estado que se autoproclama monopólio e legítimo representante do direito. Assim, nessa compreensão, além do modelo gerido pelo Estado, outras formas de organização de normatividade devem ter assegurados seu espaço, principalmente quando seus interesses e suas demandas já são regulados e resolvidos internamente. Inclusive, há casos em que expressamente o Estado reconhece a juridicidade de povos, como se efetiva com formas particulares de solução de conflitos sem participação governamental previstas no Estatuto do Índio, por exemplo (BRASIL, 1973), ou como se verifica em outras comunidades que possuem modos autônomos de resolução de dificuldades inerentes ao grupo, o que não significa a negação total do direito estatal, mas relativização de sua força e respeito a caminhos heterogêneos, que respeitem outros aspectos, como a historicidade, sociabilidade e diversidade (WOLKMER, 2015).

O pluralismo no Direito é um tema que sofre reiteradas investidas, pois enfrenta o Estado e o direito positivado. De um lado está um pensamento complexo e abrangente e, de 
outro, está o senso comum e a simplificação (MORIN, 1991, p. 23). O pluralismo não está limitado exclusivamente ao campo da juridicidade e tem sua relevância por credenciar outras formas de pluralidade (TUDELA, 2011, p. 26).

Ora, a concepção monista, de certo modo correlacionada com ideias liberais, é alicerçada no domínio e na distância, pois discursa sobre a proteção de todos os modos de vida, mas fica afastada das existências que não lhe interessam, em condição de controle e superioridade (ZIZEK, 2006, p. 39).

É o poder disciplinar referido por Foucault (2013, p. 164), que domina e restringe as multidões. O poder disciplinar visa unificar as práticas humanas para controlar. É uma forma de artificializar a vida dos indivíduos, tornando-os objetos de um sistema social.

Dentro de uma mesma ordem social é passível a coexistência dos mais variados sistemas de pensamentos e distintos meios de compreender as práticas e vivências (BARTOLOMÉ, 2014, p. 102). No Brasil há um pensamento e um desenvolvimento racional moderno que não aceitam outros modelos heterogêneos ou sustentados em outro olhar ou ponto de vista (NEGRI, 2000, p. 78).

Ocorre que para o desempenho de uma verdadeira e legítima autonomia é fundamental que haja consideração pela multiplicidade de vidas (FOUCAULT, 2008, p. 16), que analisa as circunstâncias existenciais com um contemplar histórico e cultural sem retirar sua visão da realidade, alicerçada no múltiplo, no complexo (BARTOLOMÉ, 2014, p. 102) e na completude, posto que é diferente a visão isolada de um único objeto de uma análise do todo (FOUCAULT, 2006, p. 367).

Portanto, a opção pela pluralidade de tipo insurgente, que apresenta características de uma normatividade de teor "comunitário-participativo"3 está longe do direcionamento uniforme e do pensamento único que desmerece e invisibiliza o outro (MENEZES, 2009, p. $188,200)$.

Quando se introduz a normatividade plural de insurgência vem à memória a Filosofia da Libertação, que representa a proposta de ruptura perante à hegemonia individualista eurocêntrica estabelecida. Dussel (1977, p. 7) em sua Filosofia da Libertação ${ }^{4}$ intenta uma

\footnotetext{
3 A questão aqui privilegiada de um pluralismo jurídico "comunitário-participativo" é tomando em conta o conceito operacional criado por Antonio C. Wolkmer, em sua obra "Pluralismo jurídico: fundamentos de uma nova cultura no direito". Entretanto, há de reconhecer inúmeros outros aportes sobre o pluralismo no direito, mas que, não serão examinados, como os de Boaventura de S. Santos (1977); Sally F. Moore (1986); John Griffiths ( 1986); Antonio Manuel Hespanha (2013).

4 A Filosofia da Libertação apresenta diferentes nuanças, mas, aqui, será privilegiada a leitura mais popularizada na América latina, através da interpretação de Enrrique Dussel..
} 
reflexão descolonizadora que busca romper com a exploração das "vítimas" que foram excluídas e silenciadas pela edificação da modernidade, a qual foi baseada numa dominação colonial estrangeira efetivada igualmente com amparo num cenário subalternizante com soberba indiferença a história, cultura e perspectiva, ou seja, uma colonialidade que vai além de conquistas de territórios, mas que rejeita o sentido da vida e o saber secular dos povos conquistados (MENDIETA e DE FRUTOS, 2001, p. 49).

Geopoliticamente, a periferia do Sul é o espaço de sofrer opressão e ser colonizado pela hegemonia do Norte global ${ }^{5}$. O que é resultante de um prolongado percurso histórico de aproximadamente quinhentos anos, "Mas, até quando? Não teria chegado ao seu fim a preponderância geopolítica do centro? Podemos vislumbrar um processo de libertação crescente do homem da periferia?" (DUSSEL, 1977, p. 11). É nesse sentido que a filosofia da libertação - tem a incumbência de refletir em relação à realidade, que nessa dualidade entre centro e periferia, deve indagar e intentar numa libertação, que da antiguidade até hoje se origina não de quem domina, mas sim dos dominados (DUSSEL, 1977, p. 9-10). Esse agir e insurgir dos dominados corresponde à afirmação Jean-Paul Sartre de que ainda que os espoliados tenham sido despojados, cabe apenas a estes a revolta. $\mathrm{O}$ que, em outras palavras, cabe à periferia lutar pela periferia (SARTRE, 1961). A afirmação de Sartre é corroborada por Freire (1987), que já alertava ser uma ilusão almejar que autores de projetos elitistas dispusessem de esforços e trabalho para a emancipação dos explorados, sendo completamente incongruente os algozes socorrerem suas vítimas.

Além da Filosofia da Libertação de Dussel outros aportes são somadas e refletem o contexto de busca de autonomia, como a Teologia da Libertação de Gustavo Gutiérrez (1971), Jesus Cristo Libertador, de Leonardo Boff (1972) e, do mesmo modo, a Pedagogia do Oprimido de Paulo Freire (1970), que são conjunturas teóricas de influxo a favor dos desempoderados e silenciados pela história.

A emancipação ou modificação de uma normatividade que venha fundada e originada dos povos e dos casos concretos envolvendo suas vidas como um método de reescrever a força do povo "como reapropiación del poder normativo, creando su propio Derecho objetivo hacia el interior de sus comunidades", o que segundo De la Torre Rangel (2006, p. 26, 52) no Brasil é conhecido como Direito Insurgente, o qual que vem crescendo nos setores

\footnotetext{
${ }^{5}$ Norte global e Sul global neste ponto é amparado em Enrique D. Dussel (1977) e Boaventura de Sousa Santos (2003), que entendem que há um limitada dependência de minorias do lado inverso do branco e civilizado do Norte global, por conta da dominação de um pensamento ocidental eurocêntrico e homogeneizador, que desconsidera outros olhares ou outras possibilidades.
} 
desempoderados - “[...] proletariado, clases subalternas dominadas, Pueblo” - da América Latina.

De la Torre Rangel (2006) quando se refere ao Direito Insurgente, observa que este é um tema relacionado à alternatividade do direito, ou direito insurgente (para os brasileiros), ou pluralismo jurídico - especialmente citando Wolkmer (1997, 2015) - ou, no seu entender, o "derecho que nace del pueblo". Essa emancipação, que tem em uma de suas vertentes o direito do povo ou Direito Insurgente, ou direito alternativo, foi defendida por uma corrente de advogados participantes de movimentos coletivos populares da América Latina e, posteriormente, na década de 1990, por juízes brasileiros do estado do Rio Grande do Sul. O mais importante é que todos esses movimentos sociais e seus adeptos, independentemente de suas estruturas e nomenclaturas, são caminhos contrários aos intentos neoliberais/hegemônicos num esforço e luta por articulação, debates e reformulação do direito como alternativa de emancipação (DE LA TORRE RANGEL, 2006, p. 26-28, 63, 99).

É pertinente pôr em relevo que o direito é inerente à vida social, de forma que se pode afirmar que sem sociedade ou grupos sociais não é possível ou necessário a existência do direito. Por isso o direito resulta de algum modo das influências e circunstâncias políticas, culturais, etc. Dentro dessa perspectiva, cabe destacar que Boaventura de Souza Santos, na década de 1970, realizou importante estudo sociológico no Brasil sobre o pluralismo jurídico. Para tanto, utilizou pesquisa de campo em uma favela do Rio de Janeiro, onde investigou o pluralismo numa comunidade alcunhada por Santos (1977) de Pasárgada, a qual está entre as mais importantes do Rio de Janeiro, com população maior do que muitos municípios brasileiros. No estudo de Pasárgada é analisado se o nascimento e manifestação do modo de solução de divergências pelo próprio grupo envolvido nas demandas cotidianas, observandose que a forma de solucionar os conflitos está inteiramente relacionada ao modelo normativo extralegal criado pela comunidade em um modo de solução amparado no pluralismo jurídico, o que Santos chamou de Direito de Pasárgada. Da mesma análise foi possível contemplar um ponto de vista classista do direito quando comparado ao direito estatal, já que o direito oficial é conduzido pelos grupos dominantes, enquanto o direito de Pasárgada é dirigido pelas classes dominadas; em outras palavras, o direito nascido e aplicado na favela é o direito do povo, é um pluralismo que emerge da prática (SANTOS, 1977, p. 7; 2014, p.33).

Cumpre destacar, nesse mesmo sentido, que uma modificação de possível eficácia passa pela transformação do sistema jurídico vigente, que é baseando numa dualidade social 
de classes, e é justamente no pluralismo jurídico que se observa e se constrói uma expectativa de levar um direito aos mais tolhidos pela estrutura social e estatal (WOLKMER, 2015).

A normatividade comunitário-participativa proposta por Wolkmer (2015) apresenta direcionamentos comuns presentes na juridicidade insurgente externada por Miguel Pressburger (1990, p. 5). ${ }^{6}$ Para Pressburger - na obra Direito insurgente: o direito dos oprimidos -, o direito é administrado por rituais que causam extrema burocratização, sendo o direito material ou bem da vida a ser resguardado muitas vezes pelo exorbitante formalismo como uma forma de afastamento das classes sociais mais desprestigiadas ou vulneráveis do exercício de seus direitos e de acesso ao poder, pois há, por força e intermédio do direito e sua burocracia, uma separação, uma colonização e acumulação que são fomentadas e dependem desse método. Vale referir, pela importância, que essa forma de criar e aplicar os direitos de hoje é objeto das vitórias da burguesia. Assim, esse modo de separação é oriundo de grupos liberais dominantes, que ao mesmo tempo que levantaram a bandeira da liberdade e propriedade, não deixaram de lado a perspectiva de dominação, não possibilitando ao povo ou afastando-se dele um direito que de fato o represente.

O posicionamento de Pressburger (1990) tem certa relação com a interpretação de Marcelo Lira Silva (2011), quando destaca que a exclusão do povo nos projetos liberais, traz uma ideia de Estado limitado, diametralmente contrário ao Estado Social.

Pressburger (1990, p. 7) frisa que o ato de manter o povo longe de um direito concreto, pode ser observado quando ao longo da história legislativa do Brasil se“[...] reconhece a propriedade privada fundiária [...], mas cria mecanismos que impedem o acesso a esta propriedade para os não capitalistas". Do mesmo modo, afirma que não é plausível uma legislação que põe fim à escravização e não obriga o pagamento de salários aos trabalhadores, o que bem reflete a muralha separadora e existente entre o direito e o povo.

Ainda pondera Pressburger (1993. p. 27) que há no direito insurgente “[...] um ideal impulsionador de lutas políticas das classes subalternas, modificando, restringindo ou

\footnotetext{
${ }^{6}$ Wolkmer (2015) escreve que a sociedade burguesa, enquanto seguimento social, que substituindo a antiga nobreza e a ordem eclesiástica monopoliza via economia, a dominação e utilização do Estado para resguardo e proteção dos seus interesses mercantis, baseado em um estatal normatizado, formalista e único, que omite e ignora os problemas materialmente substanciais, de modo que o direito passa ser produto vinculado as inovações decorrentes da expansão industrial, do capital e da próspera ascensão social da burguesia.

Em sentido convergente, no entender de Pressburger (1990, p. 10-11), “[...] as comunidades urbanas e rurais à margem do Estado de Direito têm criado internamente normas de conduta que têm vigência e eficácia, tal como o direito estatal normatizado [...]", sendo uma forma de solução das demandas sociais locais que leva em consideração o modo de vida e histórias destes povos, com respeito as normas de conduta própria e não outros modos com visões afastadas ou baseadas em produção ou dominação econômica. Nesse sentido, observa-se familiaridades nos pensamentos teóricos de Wolkmer e Pressburger no tocante ao pluralismo jurídico e ao direito insurgente, respectivamente.
} 
refreando o comportamento dos poderosos, ao mesmo tempo em que destas lutas se desenvolve a crítica radical da prática da sociedade". A insurgência popular por um direito que ampare essas classes subalternas, quando analisada numa perspectiva da teoria do pluralismo jurídico fundamentada em Wolkmer (2015), demonstra a existência de uma normatividade "comunitária-participativa" como proposta plural de composição do direito, com exteriorizações de sujeitos coletivos via resistência em face do formalismo estatal dominante e autoritário que caminha recuado de uma justiça social e distante de uma realidade concreta.

Outro teórico do direito insurgente é Dimas Salustino Silva (1994) - no texto Direito insurgente do negro no Brasil: perspectivas e limites no direito oficial -, que chama a atenção quanto a escassa importância dada ao tema, quando afirma que "[...] mormente por se tratar de matéria novel, seara onde se tem constatado pouca preocupação do mundo jurídico e em especial dos juristas populares [...]”. Nesse sentido, o direito insurgente é representado pela organização e rebeldia do povo negro, sendo tanto uma afronta social quanto jurídica na busca de libertação e reconhecimento.

Direito insurgente pode nascer da omissão do Estado, que enseja a solução das adversidades de uma forma alternativa do direito positivo, que é ordinariamente homogêneo. Assim, o direito insurgente faz com que haja, por parte de grupos sociais um reassenhoramento de uma autoridade normativa com base em normas criadas pelos próprios grupos usuários para deslindar as necessidades intrínsecas a sua cultura e história (DE LA TORRE RANGEL, 2006, p. 28).

Nesse contexto, evidencia-se a existência do direito insurgente quando setores populares formam sua própria normatização, que decorre das próprias lutas enfrentadas pela sobrevivência perante a sociedade moderna e dominante. É um enfrentamento, é um direito dos sujeitos coletivos em face do direito estatal, como se efetiva com o direito dos povos indígenas, direitos de comunidades campesinas, de periferias, de favelas, de quilombos. Quer dizer, há uma elevação ou autonomia jurídica desses atores diametralmente contrárias ao direito único e hegemônico indicado e delimitado pelo Estado monopolista (PALACIO, 1993, p. 71).

\section{Diáspora do povo negro: da África ao Brasil}


Embora se reconheça que seja remota - sociedades antigas - e múltipla a sua gênese, atribui-se a origem da escravização humana às sociedades ocidentais, com destaque ao Império Romano alguns séculos anteriores à era cristã. Já a invasão da América Latina pelos mercadores europeus, inicialmente, teve como propósito a escravização dos povos indígenas para trabalho nas terras ditas descobertas. No entanto, tendo em vista a dificuldade de aprisionamento e domesticação dos índios, os colonizadores preferiram sua extinção, com a consequente substituição por povos negros e transportados da África (KLEIN, 1987, p. 11, 13). Essa escravização é decorrente do projeto da modernidade já destacada por Dussel (1977), no sentido da exploração de setores como indígenas, camponeses e outros povos que tradicionalmente foram e ainda permanecem omitidos e silenciados pela edificação da modernidade. A escravização como intento da modernidade também é destacada por Mbembe (2014) como modelo eurocentrista de domínio e desumanização.

Feito esse parêntese, por conseguinte, na África, os mais distintos grupos negros viviam em total autonomia, liberdade, cultura e economia milenar. Possuíam sua organização social como em qualquer outro local. No decorrer da história das escravizações no mundo, uma das grandes diferenças entre a escravização do negro em relação à de outros povos foi a diáspora (SOARES, 1988; RODNEY, 1975). Para Darci Ribeiro (1978, p. 59), não se trata de qualquer justificação ou concordância, mas sabe-se que em outros períodos históricos da civilização humana já houve escravidão. No entanto, enquanto outros povos escravizados, em geral, permaneciam em suas terras e podiam conservar sua cultura, língua e credo, com a diáspora africana houve total dispersão e violenta separação para outro continente, numa completa desculturação, desagregação familiar e social. No Brasil, o negro se tornou apenas uma ferramenta ou animal de uso e parasitação dos latifundiários.

A escravização na América Latina em relação a outros locais, como a Europa, por exemplo, é considerada extemporânea, já que tal prática foi comum ao longo da história da humanidade, sendo poucas as civilizações que tiveram o privilégio de não escravizar parte de sua população ou povos estrangeiros, principalmente utilizando os critérios origem e cor da pele. Em períodos mais remotos, o trabalho escravo não era qualificado como importante do ponto de vista econômico, ficando basicamente para servir nos trabalhos e atividades domésticas das elites daquele período. Do século V antes de Cristo em diante é que o trabalho dos povos escravizados passou fazer parte da estratégia e desenvolvimento da economia (KLEIN, 1987, p. 11, 13; WILLIAMS, 2011). Diga-se que o trabalho passou, quase que de forma exclusiva, para os povos escravizados, havendo total dependência econômica dos 
senhores no labor gratuito e forçado (COSTA, 2012, p. 22). Ribeiro (1978, p. 42) chega a afirmar que com a escravização houve uma radicalização do modelo econômico e "A minoria rica torna-se, assim, cada vez mais poderosa e as massas subalternas, livres e escravas, cada vez mais miseráveis, agravando as tensões sociais até os limites extremos", sendo o encarceramento e sequestro de negros na África como mão de obra o principal combustível para invasão e desenvolvimento em novas terras.

Embora existam defensores da hipótese de que para haver progresso são necessários sacrifícios até mesmo humanos, não há como se admitir que o avanço de uma civilização seja fundado na dominação de pessoas como se deu com a escravização dos povos negrosafricanos. A mercantilização humana nesse período entre 1500 e 1600 foi imensa, com especial destaque para o trabalho dos negros escravizados nas plantações de cana-de-açúcar em ascensão por todo o litoral nordestino (NASCIMENTO, 1978, p. 48-49).

Destituídos de qualquer bem material ou expectativa de libertação, restava ao negro a revolta e agregação com quem quer que não fosse contrário à sua luta, como os índios e outros coletivos. A constituição e desenvolvimento dos quilombos foi resultante de uma mercancia de vidas (MOURA, 1959, p. 88-89, 92).

O Estado entendia como quilombo "[...] toda habitação de negros fugidos que passem de cinco, em parte desprovida, ainda que não tenham ranchos levantados nem se achem pilões neles" (MOURA, 1959, p. 87). De acordo com Moura, a referida conceituação de quilombo é uma passagem da "Resposta do Rei de Portugal a consulta do Conselho Ultramarino, datada de 2 de dezembro de 1740”. Era incontestável o antagonismo entre negros em contraposição aos demais seguimentos sociais e de poder. Além do que, enquanto os negros reconheciam o quilombo como território e instituição de relutância, as autoridades o avistavam como local de desertores e subversivos (MOURA, 1959, p. 87).

Dos quilombos destacados pela história, Palmares é o mais notável. O quilombo de Palmares ficava localizado em Pernambuco, local que atualmente pertence ao estado de Alagoas. Com o início na segunda metade do século XVI, logo após a chegada dos primeiros navios negreiros, esse local foi espaço de agrupamento de grande número de negros que buscavam a emancipação. Conforme Edson Carneiro (1966, p. 11) “A floresta acolhedora de Palmares serviu de refúgio a milhares de negros que se escapavam dos canaviais, dos engenhos de açúcar, dos currais de gado, das senzalas das vilas do litoral, em busca da liberdade e da segurança". O ataque e ocupação dos holandeses em Pernambuco abrandou a atenção aos negros escravizados, o que facilitou a evasão de muitos para o crescimento do 
Quilombo de Palmares, onde todos com suas habilidades contribuíam na caça, pesca, produção cerâmica, criação de pequenos animais e agricultura. Os quilombos criaram um sistema social e econômico próprio, pelo qual negociavam seus produtos com negociantes ou vizinhos, adquirindo ferramentas e armas. Palmares era o paraíso dos povos negros - no sentido de liberdade e autonomia.

Assim, o quilombo era o sonho de libertação, união e esperança dos escravizados na contínua rebelião. Terra que foi protegida e defendida corajosamente por seu povo sob a direção do mítico chefe Zumbi, que não foi o primeiro, mas foi um dos líderes e guerreiros dos Palmares, que com sua notoriedade serviu de inspiração para outros quilombos (CARNEIRO, 1966, p. 5, 11).

Ante as considerações históricas vividas pela América Latina, Neves (2003) questiona se há esperanças de soberania contra a histórica supremacia das nações colonizadoras. Realça que para que haja um amanhã melhor, faz-se relevante não deixar de lutar, uma vez que desde a colonização americana, em especial nas últimas décadas, em vista das alterações de perspectivas político-sociais, observa-se que há terreno fértil para emancipação dos povos latinos (NEVES, 2003, p. 110-111).

Partindo de um paradigma descolonial, os quilombos configuraram e ainda representam associações de oposição ao modelo de economia capitalista excludente. Os quilombolas são considerados social e horizontalmente da mesma família de populações indígenas, seringueiras e posseiros, cuja peculiaridade é a objeção das elites e a ausência de uma formalidade documental e reconhecimento de seus territórios e modo de vida, o que muitas vezes é motivo de denegação e expropriação sobre seu espaço e sua história, ainda que a legislação anuncie que sua cultura é protegida e que suas terras são legítimas (PORTOGONÇALVES; CUIN, 2016, p. 266).

Sob a ótica de Anibal Quijano (2005) há evidente proximidade entre descolonialdade e insurgência. Que a afinidade deste direito insurgente e a descolonialidade refere-se mais especificamente sobre o paradoxo e as disputas entre dominação e poder existentes sobre as sociedades e grupos periféricos com uma prorrogação e seguimento de exploração ou de colonialidade.

Do mesmo modo que Quijano (2005) revela uma afinidade entre descolonidade e insurgência, também há uma possibilidade de aproximação entre a pedagogia de Paulo Freire e a descolonialidade de Fanon, que é a "[...] atención particular que ambos dieron a la consciencia, esperanza y humanización", que pode ser vista como possibilidade de 
inquietação e recusa em face da contemporaneidade colonial, ocasionando, portanto, um porvir de esperança para outros caminhos (WALSH, 2013, p. 32-33).

Abdias do Nascimento (1980, p. 263) descreve que "Quilombo não significa escravo fugido. Quilombo quer dizer reunião fraterna e livre, solidariedade, convivência, comunhão existencial". As comunidades quilombolas correspondem e significam um avanço em termos de relações humanas, sociais e econômicas, uma vez que trabalham, produzem e decidem comunitariamente, sem o objetivo de exploração humana ou desrespeito ao ecossistema, dentro de uma autonomia coletiva e democrática, numa perspectiva do buen vivir (WOLKMER, 2015, p. 47).

Clóvis Moura (1959, p. 39-41) no mesmo sentido de Nascimento, assinala que ainda que seja pouco considerada pela cultura e história brasileira, gerações de afro-brasileiros nasceram e morreram em espaços quilombolas. Os territórios quilombolas, contrariamente ao sistema exploratório capitalista de propriedades privadas, germinavam sua economia baseada na agricultura comunitária, solidária e de subsistência. Eventuais divergências sociais eram decididas pela própria coletividade que possuía normas orais baseadas em outros precedentes, ou seja, utilizavam-se dos costumes.

A quantidade de negros escravizados que chegou ao Brasil é desconhecida, uma vez que o governo vigente em 1891 determinou a destruição dos arquivos históricos que poderiam revelar um número aproximado das pessoas prisioneiras. Nascimento (1978) enfatiza que "As estimativas são, por isso, de credibilidade duvidosa. Há uma estimativa cujos números me parecem abaixo do que seria razoável, dando 4.000 .000 de africanos importados". $\mathrm{Na}$ presença desse quadro inicial "O africano escravizado construiu as fundações da nova sociedade", sendo evidente a função que o negro exerceu para o desenvolvimento inicial da economia brasileira, pois "Ele plantou, alimentou e colheu a riqueza material do país para o desfrute exclusivo da aristocracia branca" até porque ao fim de cada dia o lugar do negro era a lamúria e prantos das correntes e senzalas. De outro lado, numa total insensibilidade e negligência estavam "[...] os latifundiários, os comerciantes, os sacerdotes católicos". Mas esse modelo de escravização - racista e espoliadora - era internacionalmente popular pela suposta generosidade dos brancos aos negros. A relação dos brancos com os negros e tratamento dado a eles eram considerados um favor, uma filantropia (NASCIMENTO, 1978, p. 49-50).

Faz-se necessária, também, uma breve abordagem sobre a legitimidade das lutas dos povos remanescentes de quilombos (WOLKMER; SOUZA FILHO; TARREGA, 2016). 
Enquanto travam lutas sociais, que por sua natureza são coletivas, seus integrantes praticam pedagogias, pois nas lutas há reflexão, preparação, estudo que, de modo geral, são contrários a um modelo colonial prevalacente, que priva as vivências, que agrilhoa, que desumaniza. Portanto, vê-se um diálogo e confluência entre concepções pedagógicas e descoloniais (WALSH, 2013, p. 29). A pedagogia em forma de luta e libertação referida por Walsh (2013) já foi objeto de estudos de Paulo Freire (1967), que afirmara que a sociedade brasileira é dotada de antagonismos, eis que temos um grupo que pretende "[...] uma sociedade sem povo, comandada por uma 'elite' superposta a seu mundo, alienada, em que o homem simples, minimizado e sem consciência desta minimização, era mais 'coisa' que homem" (FREIRE, 1967, p. 35). Em seus escritos da década de 1960 esse autor já afirmava que as elites brasileiras são contrárias ao desenvolvimento e à educação do povo, pois povo educado é povo que deixa de ser coisa; e povo emancipado requer seu espaço e seus direitos. A educação do povo é elementar, mas é necessária uma pedagogia que não seja aliciadora ou colonizadora, que faça que o povo seja um sujeito social e não apenas coisa; um povo que reflita, critique e lute por sua história e seja dono de seu futuro. Pedagogia enquanto decolonização é tudo que alguns governos não toleram, pois preferem a alienação do povo, embora na maioria das vezes usem de discursos vazios em que se dizem e se colocam na condição de protetores da população; também "[...] destorcem sempre a realidade e insistem em aparecer como defensoras do Homem, de sua dignidade, de sua liberdade", sendo parte da estratégia de dominação retirar a reflexão e consciência das pessoas (FREIRE, 1967, p. 3536).

Fundado nessas premissas, "Los esclavos, como pueblo con esperanza [...] tenían sobre su imaginación. Esta imaginación pedagógica les permitia mitigar y resistir las formas em que la aflicción destroza al alma" (HAIMES, 2007 apud WALSH, 2013, p. 25). Não custa enfatizar que "[...] mediantes sus canciones, cuentos [...] los esclavos se enseñaban a sí mismos el significado moral y ético de crear um sentimento de pertinência comunitária" (HAIMES, 2007 apud WALSH, 2013, p. 25). É importante referir, no ponto, em face de sua extrema pertinência, que essa pedagogia dos escravizados objetivava transformar a aflição em esperança, isto é, a práxis da resistência funcionando como uma metodologia de aprendizado e perspectiva de encerramento de toda forma de desacorrentamento (WALSH, 2013, p. 36-37).

Nesse viés, os africanos logo que chegaram no Brasil iniciaram sua luta por liberdade: "Foi, inicialmente, o quilombo, a forma adotada. Fugiam para as matas, tornando-se um 
perigo constante ao sossego dos senhores de terras e de engenhos" (MOURA, 1959, p. 90). Essas ponderações refletem as preocupações dos dominadores com as insurreições do negro escravizado no Brasil.

A histórica luta dos negros no Brasil é demonstrativa da resistência e oposição ao opressor sistema colonial e capitalista. Foram justamente os quilombos os locais representativos da vivência e tentativa de rompimento de dominação contra a estrutura mercantilista então vigorante, de forma que “[...] sua existência durante todo o regime colonial e imperial, representou a desmoralização do aparato jurídicoideológico instalado para combatê-los" (TRECCANI, 2006, p. 41), o que significou um amedrontamento, inclusive do ponto de vista econômico, tornando os quilombos objeto de perseguição e total refutação pela sociedade escravocrata.

O sofrimento do povo negro, seja na travessia da África, seja posteriormente no Brasil, reflete o modo como o europeu tratava outros povos (LAS CASAS, 2011, p. 33).

Abdias do Nascimento (1980, p. 5, 261-263) externa que os africanos e seus descendentes sofreram apavoramentos e atrocidades ante a diáspora imposta pela colonização. Ressalta que o Estado, além de privilegiar os segmentos sociais dominantes, foi o instrumento político de uso de elites na investida escravagista contra os povos vindos da África.

Em face dessa histórica associação entre Estado e elites, o afrodescendente pauta por resistência e que os agentes da segregação precisam ser enfrentados. Esse enfrentamento não é no sentido de conquistar alguns poucos direitos dentro de uma ordem social fragmentada capitalista. Ao negro cabe lutar por uma mudança na estrutura que sustenta os aliados e contrários à emancipação negra. A resistência ativa do negro é o quilombismo que para Nascimento, representa revolta e investigação de possibilidades para enfrentamento do racismo nos moldes históricos emancipatórios já utilizados nos quilombos. Que a luta pela vida desses coletivos no passado e que a experiência autonômica dos quilombos sirvam de paradigma emancipatório. Ao longo de aproximadamente cinco séculos, tais identidades no Brasil suportaram a opressão branca, eurocentrista, elitista e desumanizadora. O quilombismo é a forma recente de continuarem a propagação da autodeterminação, da dignidade, de "uma sociedade cuja natureza intrínseca torne impossível a exploração econômica e o racismo", ou seja, "uma democracia autêntica, fundada pelos destituídos e os deserdados deste país, aos quais não interessa a simples restauração de tipos e formas caducas de instituições políticas, sociais e econômicas" (NASCIMENTO, 1980, p. 262). Assim como ocorreu nos quilombos, 
que o racismo seja enfrentado e que seja "Proclamada a falência da colonização mental eurocentrista", celebrando "o advento da libertação quilombista", podendo esta enquanto concepção de libertação amparada na história de batalha, possibilitar ao negro participar político e socialmente despido de amarras impostas pelo racismo e elevado a participante e autor de sua história e liberdade (NASCIMENTO, 1980, p. 5, 261-263).

\section{Cinco séculos de insurgência contra-hegemônica}

O povo negro não ficou inerte, ainda que atacado fisicamente - torturas - ou ideologicamente - cristianismo -, agindo ao seu modo, seja tirando a própria vida, seja se insurgindo e tentando fugas (NASCIMENTO, 1978, p. 59-60). Nesse período o quilombo correspondeu, seguramente, a um horizonte e santuário de perseverança e oposição. $\mathrm{O}$ quilombo era "Pequeno ou grande, estável ou de vida precária, em qualquer região em que existia a escravidão, lá se encontrava ele como elemento de desgaste do regime servil" (MOURA, 1959, p. 87). Não era taxativamente reduzido a locais específicos e tranquilos. Seu surgimento, refazimento e expansão dependiam da escravidão e inconformismo. A constituição dos quilombos dependia de uma natural seleção de um comportamento de revolta. Ainda que por simples amostragem, observa-se que "Em Minas Gerais, Mato Grosso, Goiás, Pernambuco, Alagoas, Sergipe, Maranhão, onde quer que o trabalho escravo se estratificava, ali estava o quilombo, o mocambo de negros fugidos, oferecendo resistência. Lutando" (MOURA, 1959, p. 87). Essa luta enfrentava a intolerância do poder econômico, assim como a procura incansável por capturas e as investidas militares do Estado que legitimavam e garantiam os moldes da escravidão

Convém anotar que as insurgências ocorreram desde a chegada dos primeiros escravizados ao Brasil. Um dos acontecimentos mais memoráveis dentro da história do povo negro durante este trágico período foi a formação dos quilombos, como o consignado no "[...] século XVI: a República dos Palmares, verdadeiro estado africano constituído no seio das florestas de Alagoas por rebeldes e fugitivos escravos" (NASCIMENTO, 1978, p. 59-60) que ali presente como uma "'Troia Negra' resistiu a mais 27 expedições militares enviadas por Portugal e pelos holandeses" (NASCIMENTO, 1978, p. 59-60). Palmares chegou a possuir em torno de trinta mil integrantes e representou a voz de pessoas sequestradas de sua pátria, significou durante muito tempo o sonho e a liberdade de um povo (NASCIMENTO, 1978). 
E ter liberdade é um dos mais meritórios resultados de uma revolução (ARENDT, 2011, p. 45).

Esse discrepante caminhar é reflexo da construção social brasileira firmada no poder da acumulação agrária, na exploração da mão de obra rural, no trabalho escravo e na hostilidade contra as pessoas que efetivamente viviam e sobrevivem plenamente da terra. Quilombolas, indígenas e outros camponeses de subsistência, na condição de povos que tradicionalmente ocupam terras rurais e florestas, descendentes de uma despótica história alicerçada na injustiça agrária, além de vítimas de um sistema capitalista de concentração, são considerados um obstáculo, com ataques de enjeitamento e tentativa de elevá-los à marginalização, uma agressão racial e classista, que no Brasil atual é empreendida por grandes conglomerados empresariais de setor agropecuário e minerário. Esses povos tradicionais são classificados como inconvenientes, ainda que haja legislações que especifiquem a obrigatoriedade da proteção de suas terras e cultura (PORTO-GONÇALVES; CUIN, 2016, p. 242, 257-258).

A história de exploração dos negros é resultante de uma extremada e confrontada luta e resistência contra a ambição do capitalismo. Esses povos, que possuem marcas de agonia e embate ante ao modo colonizador a que foram submetidos, "[...] tentam libertar-se das hierarquias raciais e cuja intelligentsia constrói uma consciência colectiva que [...] combate as dimensões ontológicas resultantes da construção dos temas acerca da raça" (MBEMBE, 2014, p. 62-63), em uma violenta e reprovável dominação física e moral.

A análise de Mbembe (2014) faz rememorar Paulo Freire (1987, p. 34, 36, 63) no sentido de que não se pode rejeitar que todos têm valores e visões; mas a indagação é se as perspectivas são de respeito ou de opressão.

Ainda cabe lembrar que a questão da cor da pele, os traços físicos, os adornos e a expressão cultural têm sido motivo, ao longo do tempo, das principais perseguições, intolerâncias e submissão, na busca tanto da segmentação de raças, como a "[...] unidade de medida da diferença e da inimizade, o critério determinante da luta pela vida, o princípio de eliminação, de segregação ou de purificação da sociedade" (MBEMBE, 2014, p. 101). Esse modo de desmembramento social é um projeto da modernidade eurocêntrica que expandiu ao mundo a sua maneira imperialista de conquistas, desconsiderando e desumanizando outros povos, o que Mbembe chama de "projecto europeu de expansão sem limites que se desenvolve a partir dos últimos anos do século XVIII" (MBEMBE, 2014, p. 101), até porque foi do final do século XVIII em diante que houve uma desmedida propagação do 
colonialismo europeu diante do mundo com a utilização de todos os arranjos autoritários possíveis, como o bélico, a religião e o comércio, numa espécie de campanha imperialista de intervenção e controle sobre povos e nações.

Ainda que sejam considerados autores que tratam sobre as sequelas do colonialismo, a análise de Mbembe (2014) vai ao encontro da reflexão de Stuart Hall, de que é necessário entender, trabalhar e utilizar os recursos do saber para interpretar a sociedade que insensivelmente barbariza as pessoas (HALL, 1997, p. 23).

Foucault (2013, p. 172) traz marcante análise sobre a influência do poder sobre a população quando afirma que "O indivíduo é, sem dúvida, o átomo fictício de uma representação 'ideológica' da sociedade; mas é também uma realidade fabricada por essa tecnologia específica de poder que se chama a "disciplina". Aponta que o poder produz efeitos em face das pessoas desconsiderando, recusando e invisibilizando suas necessidades e individualidades.

Walsh (2013, p. 24) tem um ponto de vista similar ao Foucault, pois entende que há uma desagregação e uma transformação de poder pelas quais " [...] governos auto-intitulados governos progressistas", distanciando do neoliberalismo e se aproximando do "[...] neoextrativismo e criminalização do protesto", o que é uma das espécies ou modos de retrocesso contemporâneo.

Nesse contexto sinóptico, desde a África até a atualidade, a legislação que traz fim a escravização - Lei Áurea de 1888 - não foi voluntariosa e sequer citou o negro nos seus dois reduzidos e simplórios artigos (SOARES, 1988, p. 19).

A insurgência dos negros tolhidos de liberdade foi a grande cicatriz imposta na face da sociedade da época, uma vez que "A desobediência sistemática, a lentidão na execução das tarefas, a sabotagem da produção e as fugas individuais ou coletivas foram algumas delas. Fugir sempre fazia parte dos planos." Isso assombrava o governo e os colonizadores inconformados com o ato do negro em suportar e confrontar o padrão vigente (ALBUQUERQUE e FRAGA FILHO, 2006, p. 117-119).

A retirada forçada do povo negro da África para América pelos europeus serviu para amparar e expandir o capitalismo. "A escravidão foi o regime de trabalho preponderante na colonização do Novo Mundo; o tráfico negreiro, que alimentou, um dos setores mais rentáveis do comércio colonial" (NOVAIS, 1990, p. 78-80)., até porque nos países então colonizados o trabalho forçado e gratuito constituiu a base do crescimento econômico das 
elites que por suas próprias mãos não teriam acumulado e sobrevivido economicamente (NOVAIS, 1990).

A escravização, colonização e, em última instância, o avanço do capitalismo, conseguiram afetar tanto a África como a América concomitantemente. Na África, a colonização destruiu tribos e comunidades inteiras. No Brasil, os que chegaram com vida, restaram ultrajados e violentados completamente. A raça foi o estopim desta batalha desagregadora que fez parte da história afro-brasileira (MBEMBE, 2014, p. 104) e que foi apoiada por parte considerável de religiosos aparelhados aos invasores europeus à América e ao Brasil (NASCIMENTO, 1978; VALENTE, 1987).

Ao longo da memória humana houve e ainda se está transitando por dissensões raciais, que muito se assemelham às disputas entre burguês e proletários e senhores contra escravizados. Não obstante, há uma descomunal vantagem do ponto de vista legal entre esses grupos antagônicos, já que apenas um lado possui em seu poder o prestígio e mando para criar e modificar as legislações, assim como maiores facilidades de acesso para ocupar espaços (MBEMBE, 2014, p. 262). Claro que estas desvantagens do negro em relação ao branco têm raízes históricas profundas, já que a África foi tomada e dividida pelos brancos europeus (BRUNSCHWIG, 1993, p. 13 e 71; RODNEY, 1975).

O combate do povo negro não foi apenas de resistência à escravização. A luta não foi tão somente contra o senhor e explorador direto de sua força de trabalho e de seu corpo. Foi, ademais, em direção oposta a um sistema de colonização. "Tratava-se também de um saber que ligava indissociavelmente a crítica da vida e a política da luta e do trabalho requerido para escapar à morte". Veja-se que o colonialismo desumanizou os povos e os transfigurou em objetos e instrumento de trabalho, de forma que a resistência desses grupos vilipendiados não era contra um inimigo específico, mas sim contrariamente à estrutura reinante (MBEMBE, 2014, p. 282).

Assim, a luta do negro representada na atualidade pelos remanescentes de quilombos, uma insurgência em contraposição aos colonizadores europeus e aos senhores do Brasil. O europeu que se intitulou como colonizador furtou dos povos vindos da África a sua história e identidade em uma animalização e trabalho gratuito, que resultaram ainda mais em concentração econômica e solidificação dos latifúndios dos proprietários de terras. Presentemente, a luta ainda é legítima, embora muitas vezes não seja contra formas de castigo ou fuga, mas é uma luta política e ideológica, uma vez que ao negro ainda é inibida a 
cidadania plena; basta verificar a violência do sistema prisional e policial contra esse povo (RIBEIRO, 1978; NASCIMENTO, 1978; NOVAIS, 1990; MBEMBE, 2014).

Como observa Dimas Salustino da Silva (1994, p. 69) "Os Quilombos não são apenas o exemplo do passado [...] foram a mais bem sucedida forma de luta contra a exploração escravocrata”. E esse confronto contra a exploração é um modo de cidadania forjado em uma coerção que coloca em dubiedade a afirmativa de que apenas o Estado tem força jurisdicional - daí o resposta pelo pluralismo jurídico. O que resulta na constatação de que uma normatividade interna de uma coletividade, ainda que consuetudinária, pode amparar a luta pela liberdade ou território independente da legislação oficial. Isso representa uma reinvenção de um direito construído na realidade e na insistência - direito insurgente - de povos marginalizados contrários as opressões econômicas e governamentais.

Logo, com essas considerações, há que se ter presente que “[...] a cultura jurídica nacional foi sempre marcada pela ampla supremacia do oficialismo estatal sobre as diversas formas de pluralidade de fontes normativas que já existiam” (WOLKMER, 2015, p. 89). Assim, do ponto de vista sócio-histórico, verifica-se um liame entre o pluralismo jurídico com a luta dos quilombolas pela humanização, uma vez que esse inconformismo e contrariedade é oriundo de uma pluralidade normativa insurgente baseada na experiência e memória desse povo.

\section{Conclusão}

Diante de todo panorama exposto, que tratou do pluralismo jurídico - e a contrahegemonia dos povos remanescentes de quilombo - como uma hipótese de alteridade, com aprofundamento e a revisão histórica do exteriorizado por experiências populares. Um pluralismo com indispensável relevância teórico-científica, uma vez que há uma diversidade cultural merecedora de consideração, rompendo-se a visão excludente e hegemônica, que acolha uma real consolidação e uma práxis social plural com as mais variadas formas de viver, com ênfase aos povos remanescentes de quilombos, dentre outros povos.

A seu turno, denotou-se que os povos negros experimentaram e ainda enfrentam o longo distanciamento entre o modelo jurídico positivo-burguês e a realidade social, no padrão hegemônico tocante aos aspectos de uma interdependência cultural, política e social.

Esse estudo compreendeu o itinerário do povo afro-brasileiro desde a chegada dos primeiros navios europeus da África, carregados de seres humanos sequestrados e 
escravizados, os enfrentamentos, o surgimento dos quilombos e a situação dos povos quilombolas. Bem assim, a relação do povo negro com a teoria do pluralismo jurídico - no sentido de sua contínua insurgência -, enquanto instrumental reflexivo para emancipação, embora concomitante com as formas excludentes do monismo jurídico estatal dominante e dominado pelas elites latifundiárias hegemônicas.

Apresentou-se a situação destes povos tradicionais, para compreensão e legitimidade de suas lutas, a fim de destacar que uma sociedade na perspectiva do pluralismo respeita os povos históricos e harmoniza todos suas coletividades, independentemente de sua forma de vida, de sua origem ou suas características específicas linguísticas e culturais.

Neste sentido, a vida humana, considerando as questões inerentes a convivência, está envolvida constantemente em conflitos sociais que emergem das diferenças étnicas-culturais, estilos de vida, idiomas e costumes. Isso significa que o pluralismo jurídico nasce da busca por uma alternativa jurídica que possibilite a grupos, em especial os mais vulneráveis ou furtados de suas famílias e terras, o amparo não apenas em uma única fonte de direito ou de solução, mas outras, fora da fonte positiva e estatal, através da prática insurgente enquanto busca de direitos inerentes a grupos sociais, de forma mais democrática e participativa.

Por sua vez, a terminologia remanescente de quilombos não deve ser limitada a um espaço ou território, mas à revolta e indignação - direito insurgente - diante dos muros da segregação e do racismo ainda vigentes. Logo, as reminiscências de quilombos vão muito além de monumentos ou lembranças, sendo nomenclatura que em tempo recente significam reivindicação e militância.

Em suma, a realidade plural de um direito insurgente fica revelada quando grupos coletivos ou novas sociabilidades formam sua própria organização, instituindo seus espaços de lutas pela sobrevivência diante de múltiplas formas de opressão e exclusão da sociedade. Trata-se do enfrentamento ao formalismo estatal excludente, em que a pluralidade normativa insurgente se revela como direito dos povos remanescentes de quilombos, cuja manifestação das práticas sociais materializa-se na força instituinte e na conquista de novos e de autênticos direitos enquanto expressão da pluralidade e da diversidade.

\section{Referências}

ALBUQUERQUE, Wlamyra; FRAGA FILHO, Walter. Uma história do negro no Brasil. Rio de Janeiro. Fundação Cultural Palmares, 2006. 
ARENDT, Hannah. Sobre a revolução. São Paulo: Companhia das Letras. 2011.

BARTOLOMÉ, Miguel. El regreso de la barbarie: una crítica etnográfica de las ontologías "premodernas". Antropología y Ciencias Sociales, n 16, jun. 2014

BAUMAN, Ziygmunt. Eentrevista com o sociólogo. 2014. Disponível em: http://www.paulobach.com.br/2015/10/06/zygmunt-bauman-sobre-facebook/. Acesso em: 10 nov. de 2019.

BAUMAN, Zygmunt; BORDINI, Carlo. Estado de crise. Lisboa: Relógio D’Água, 2016.

BRASIL. [Constituição (1988)]. Constituição da República Federativa do Brasil de 1988. Brasília, DF: Presidência da República, [2016]. Disponível em: http://www.planalto.gov.br/ccivil_03/Constituicao/Constituiçao.htm. Acesso em: 7 set. 2019.

BRUNSCHWIG, Henri. A partilha da África negra. São Paulo: Editora Perspectiva, 1993.

CARNEIRO, Edson. O quilombo dos palmares. Rio de Janeiro. Ed. Civilização Brasileira, 1966.

CÉSAIRE, Aimé. Discurso sobre el colonialismo. Madrid: AKAL, 2006.

COSTA, Pietro. Poucos, muitos, todos: lições de história da democracia. Tradução de Luiz Ernani Fritoli. Curitiba: Editora UFPR, 2012, cap. 26, pg. 299-308.

DE LA TORRE RANGEL, Jesús Antonio. El derecho como arma de liberación en América Latina. Sociología jurídica y uso alternativo del derecho. San Luis Potosí.CENEJUS, Centro de Estudios Jurídicos y Sociales P. Enrique Gutiérrez, Facultad de Derecho de la Universidad Autónoma de San Luis Potosí, México, 2006.

DUSSEL, Enrique D. Filosofia na América Latina: filosofia da libertação. São Paulo: Loyola, 1977.

DUSSEL, Enrique D. Hacia una filosofía política crítica. Bilbao: Desclée de Brouwer, 2001.

FANON, Frantz. Pele negra, máscaras brancas. Trad. Renato Silveira. Salvador: Edufba, 2008.

FOUCAULT, Michel. A hermenêutica do sujeito. São Paulo: Martins Fontes, 2006. Curso dado no College de France (1981-1982)

FOUCAULT, Michel. Segurança, território, população. São Paulo: Martins Fontes, 2008. Curso dado no College de France (1977-1978).

FOUCAULT, Michel. Vigiar e punir: nascimento da prisão. Petrópolis: Vozes, 2013.

FREIRE, Paulo. Educação como prática de liberdade. Rio de Janeiro: Editora Paz e Terra, 1967. 
FREIRE, Paulo. Pedagogia do oprimido. Rio de Janeiro. Edições Paz e Terra, 1987.

GONZALEZ, Lélia. Por um feminismo Afro-latino-Americano. São Paulo: AfroLatinoAmérica, 2011.

GRIFFITHS, John. What is legal pluralismo? Journal of Legal Pluralism. N.24, 1986.

HALL, Stuart. Da Diáspora. Identidades e Mediações Culturais. Belo Horizonte: UFMG, 2003.

HALL, Stuart. The work of representation. In: HAKK, Stuart. Representation, cultural representations and signifying practices. Londres: Sage Publicantions, 1997.

HESPANHA, Antonio Manuel. Pluralismo Jurídico e Direito Democrático. São Paulo: Annablume, 2013.

KLEIN, Herbert S. El tráfico atlántico de esclavos. Lima: IEP/Fundación M.J.Bustamente De La Fuente, 2011.

KLEIN, Herbert S. Escravidão africana: América Latina e Caribe. São Paulo: Editora Brasiliense, 1987.

LAS CASAS, F. Bartolomeu. O paraíso destruído: a sangrenta história da conquista da América Espanhola. Tradução de Heraldo Barbuy. Porto Alegre. L\&PM. 2011.

LEITE, Ilka Boaventura. Quilombos e quilombolas: cidadania ou folclorização. Horizontes Antropológicos. Porto Alegre, ano 5, n. 10, p. 123-149, maio 1999. Disponível em: http://www.scielo.br/pdf/ha/v5n10/0104-7183-ha-5-10-0123.pdf. Acesso em: 3 de out. 2019.

MBEMBE, Achille. Crítica da razão negra. Ed. Antígona. Portugal, 2014.

MBEMBE, Achille. Prefácio. In: FANON, Franz. Oeuvres. Paris: La découverte, 2011.

MENEZES. Ana Paula. Colonialidad del poder, eurocentrismo y América Latina. En E. Lander (Ed.), La colonialidad del saber: eurocentrismo y ciencias sociales. Perspectivas Latinoamericanas. La Habana: Editorial de Ciencias Sociales, 2005.

MORIN, Edgar. A cabeça bem-feita: repensar a reforma, reformar o pensamento. 18. ed. Rio de Janeiro: Bertrand Brasil, 2010.

MORIN, Edgar. Introdução ao pensamento complexo. Lisboa: Instituto Piaget, 1991.

MOORE, Sally F. Legal systems of the world: na introductory guide to classifications, typological interests and bibliographic resources. In: LIPSON, Leon; WHEELER, Stanton (Eds.) Law and the social sciences. New York: Russell Sage Foundation, 1986.

MOURA, Clóvis. Rebeliões da senzala. São Paulo, Lech Livraria Editora Ciências Humanas, 1959. 
NASCIMENTO, Abdias do. O genocídio do negro brasileiro: processo de um racismo mascarado. Rio de Janeiro: Paz e Terra,1978.

NASCIMENTO, Abdias do. Quilombismo. Rio de Janeiro: Vozes, 1980.

NEGRI, Toni. Arte y multitudo. Ocho cartas. Madrid: Trotta, 2000.

NOVAIS, Fernando. Estrutura e dinâmica do antigo sistema colonial. São Paulo: Brasiliense, 1990.

PALACIO, German. Pluralismo Jurídico. Bogotá: Universidad Nacional de Colombia, 1993.

PAZELLO, Ricardo Prestes. Direito insurgente: fundamentações marxistas desde a América Latina. Rev. Direito e Práx., Rio de Janeiro, 9, n. 3, p. 1555-1597, 2018.

PORTO-GONÇALVES, Carlos Walter; CUIN, Danilo Pereira. Geografia dos conflitos por terra no Brasil (2013): Expropriação, violência e r-existência. In: FLORES, Pavel C. López; GUERREIRO, Luciana García. (Coord.). Pueblos originarios en lucha por las autonomías: experiencias y desafíos en América Latina. Buenos Aires: El Coletivo, Buenos Aires, 2016. (Grupo de Trabajo CLACSO).

PRESSBURGER, Miguel. Direito insurgente: o direito dos oprimidos. In: RECH, Daniel et al. Direito insurgente: o direito dos oprimidos. Rio de Janeiro: Instituto Apoio Jurídico Popular, 1990. (Coleção Seminários, n. 14).

PRESSBURGER, Miguel. O Direito como instrumento de mudança social. In: FRAGOSO DE CASTRO, Marcelo Francisco. Direito e mudança social. Rio de Janeiro: CCJE/UFRJ, 1993, p. 27-34.

QUIJANO, Aníbal. Colonialidad del poder, eurocentrismo y América Latina. En E. Lander (Ed.), La colonialidad del saber: eurocentrismo y ciencias sociales. Perspectivas Latinoamericanas. La Habana: Editorial de Ciencias Sociales, 2005.

RIBEIRO, Darci. O processo civilizatório. São Paulo: Círculo do Livro, 1978.

RODNEY, Walter. Como a Europa Subdesenvolveu a África. Lisboa: Serra Nova, 1975.

RODRIGUES, Nina. Os africanos no Brasil. Brasília: Companhia Editora Nacional, 4ª Ed., 1976.

SANTOS, Boaventura de Sousa. La caída del angelus novus: ensayos para una nueva teoría social y una nueva práctica política. Bogotá: Editora ILSA, Universidad Nacional de Colombia, 2003.

SANTOS, Boaventura de Sousa. NUNES, João Arriscado. Introdução: para ampliar o cânone do reconhecimento, da diferença e da igualdade. In: SANTOS, Boaventura de Sousa (Org.). Reconhecer para libertar: os caminhos do cosmopolitismo multicultural. Rio de Janeiro: Civilização Brasileira, 2003. 
SANTOS, Boaventura de Sousa. The law of the oppressed: the construction and reproduction of legality in Pasargada. Law \& Society Review. Denver, v. 12 n. 1, 1977.

SANTOS, Boaventura de Souza. O Direito dos Oprimidos. Coimbra: Almedina, 2014.

SARTORI, Giovanni. La democracia en 30 lecciones. México: Taurus, 2009.

SARTRE, Jean-Paul. O existencialismo é um humanismo. Trad. e notas de Vergílio Ferreira. Lisboa: Presença, 1961.

SILVA, Dimas Salustiano da. Direito Insurgente do Negro no Brasil: perspectivas e limites no Direito oficial. In: CHAGAS, Sílvio D. (Org.). Lições de Direito Civil Alternativo. São Paulo: Acadêmica, 1994, p. 57-71

SILVA, Marcelo Lira. Os fundamentos do liberalismo clássico: a relação entre estado, direito e democracia. Aurora. ano 5, n. 9, - dez. 2011.

SIMÓN, Pablo. El príncipe moderno: democracia, política y poder. Madri: Editora Debate, 2018.

SOARES, Natalício. A didática e o negro. Curitiba: Artes Gráficas, 1988. (Série: Centenário da Abolição 1888 - 1988).

TRECCANI, Girolamo Domenico. Terras de quilombo: caminhos e entravés do processo de titulação. Belém, Secretaria Executiva de Justiça. Programa Raízes, 2006, p. 41.

TUDELA, Farit Rojas. Del monismo al pluralismo jurídico: interculturalidad en el Estado constitucional. Los derechos individuales y derechos colectivos en la construcción del pluralismo jurídico en América Latina. La Paz: Fundación Konrad Adenauer, 2011, p. 21.

VALENTE, Ana Lúcia E. F. Ser negro no Brasil hoje. São Paulo: Moderna, 1987.

WALSH, Catherine. Pedagogía decoloniales: prácticas insurgentes de resistir, (re)existir y (re)vivir. Quito: UASB/Abya Yala, 2013.

WILLIAMS, Eric. Capitalismo y Esclavitud. Madrid: Traficantes de Sueños, 2011.

WOLKMER, Antonio Carlos. Pluralismo jurídico: fundamentos de uma nova cultura no direito. 4ed. São Paulo: Saraiva, 2015.

WOLKMER, Antonio Carlos; FAGUNDES, Lucas Machado. Tendências contemporâneas do constitucionalismo latino-americano: Estado plurinacional e pluralismo jurídico. Pensar, Fortaleza, v. 16, n. 2, p. 371-408, jul./dez. 2011.

WOLKMER, Antonio Carlos; SOUZA FILHO. Carlos F. Marés de; TARREGA, Maria Cristina V.B. Os Direitos Territoriais Quilombolas. Além do Marco Temporal. Goiânia: Ed. PUC/GO, 2016. 
ZIZEK, Slavoj. Elogio da intolerância. Lisboa: Relógio d’Água, 2006. 